\title{
Alimentação Escolar no Brasil e Estados Unidos: uma revisão integrativa
}

\author{
School Food in Brazil and the United States: \\ an integrative review
}

\author{
Josiane Tiborski Cesar ${ }^{1}$ \\ Emanuele de Araújo Valentim ${ }^{1}$ \\ Claudia Choma Bettega Almeida ${ }^{1}$ \\ Maria Eliana Madalozzo Schieferdecker ${ }^{1}$ \\ Suely Teresinha Schmidt ${ }^{1}$
}

${ }^{1}$ Programa de PósGraduação em Alimentação e Nutrição, Departamento de Nutrição, Universidade Federal do Paraná. Av. Prefeito Lothário Meissner 632, Jardim Botânico. 80210-170 Curitiba

PR Brasil.

josi.tice@hotmail.com

\begin{abstract}
This paper is an integrative review of the literature that sought to identify the factors that influence the adhesion and acceptance of school food among Brazilian and American students, and to show the main differences between the programs of these two countries. the following databases were consulted: Latin American and Caribbean Health Sciences (Lilacs); Pubmed; Scientific Electronic Library Online (Scielo); and Science Direct. Data were collected between July and August 2015, using the following key words in Portuguese and English: "adherence to school food" (adesão à alimentação escolar), "accepting of school feeding" (aceitação à alimentação escolar) and the "National School Lunch Program" ("Programa Nacional de Alimentação Escolar"). The search resulted in 7 Brazilian articles and 7 Americans articles published between 2004 and 2014, besides the current laws of each program, selected in the electronic sites of agencies responsible for administrating them. After descriptive and comparative analysis, the results revealed that adherence and acceptance are low in both programs, and they are influenced by socioeconomic factors, competitive foods present in the school environment and students' food preferences.
\end{abstract}

Key words Public policies, School food
Resumo Trata-se de uma revisão integrativa da literatura que teve como objetivo identificar os fatores que influenciam a adesão e a aceitação da alimentação escolar entre estudantes brasileiros e americanos, e apontar as principais diferenças entre os programas desses dois países. A busca dos trabalhos científicos foi realizada nas bases de dados da Literatura Latino-Americana e do Caribe em Ciências da Saúde (Lilacs), Pubmed, Scientific Eletronic Library Online (SciELO) e Science Direct. Os dados foram coletados no período de julho a agosto de 2015, utilizando os seguintes descritores em português e inglês: "adesão à alimentação escolar" (adherence of school feeding), "aceitação à alimentação escolar" (accepting of school feeding), "Programa Nacional de Alimentação Escolar" e "National School Lunch Program". A busca resultou em 07 artigos brasileiros e 07 artigos americanos, publicados entre os períodos de 2004 a 2014, além das legislações vigentes de cada programa, selecionadas nos sites eletrônicos dos órgãos responsáveis pelo gerenciamento dos mesmos. Após análise descritiva e comparativa, os resultados demonstraram que a adesão e a aceitação foram baixas em ambos os programas, e que são influenciadas por fatores socioeconômicos, alimentos competitivos presentes no ambiente escolar e pelas preferências alimentares dos alunos. Palavras-chave Políticas públicas, Alimentação escolar 


\section{Introdução}

Crianças e adolescentes de várias partes do mundo são beneficiados com a alimentação escolar (AE). A oferta da alimentação saudável nas escolas é uma maneira de apoiar o desenvolvimento infantil por meio da nutrição adequada e da melhoria das habilidades cognitivas dos estudantes, além de contribuir para diminuição da evasão escolar ${ }^{1}$.

Além disso, programas de alimentação escolar são destaques em diversos países como parte de sistemas de proteção social e ao possibilitar o desenvolvimento local sustentável, com a utilização de alimentos da produção agrícola local, cooperando com comunidades vulneráveis ${ }^{1}$. Dessa maneira, os programas atuam dentro da perspectiva de promover a Segurança Alimentar e Nutricional (SAN), em todas as suas dimensões, ou seja, disponibilidade, acesso e utilização dos alimentos e nutrientes ${ }^{2,3}$.

Segundo a Organização das Nações Unidas para Alimentação e Agricultura (FAO), a garantia de segurança alimentar acontece "quando todas as pessoas, em todos os momentos, têm acesso físico, social e econômico a uma alimentação suficiente, segura e nutritiva que atenda às suas necessidades nutricionais e preferências alimentares para uma vida ativa e saudável"2,3. No Brasil, o conceito tem a visão mais abrangente que permite a melhor compreensão das inter-relações entre as dimensões de SAN: "direito de todos ao acesso regular e permanente a alimentos de qualidade, em quantidade suficiente, sem comprometer o acesso a outras necessidades essenciais, tendo como base práticas alimentares promotoras da saúde que respeitem a diversidade cultural, econômica e socialmente sustentável" ${ }^{\text {"3,4 }}$.

Nesse sentido, o ambiente escolar é o espaço estratégico e fundamental para a promoção da SAN entre os escolares, por possibilitar o fornecimento de refeições e também atuar na formação de hábitos alimentares saudáveis, sendo que o consumo da AE pelos estudantes é um ponto chave para o alcance desse objetivo. Em todo o mundo, 169 países fornecem alimentação escolar à aproximadamente 368 milhões de estudantes. Os países com os maiores programas em número de beneficiados são a Índia (114 milhões), seguido pelo Brasil (47 milhões) e Estados Unidos (45 milhões) ${ }^{1}$.

No Brasil, o Programa Nacional da Alimentação Escolar (PNAE) destaca-se por ser o programa social mais antigo voltado para a questão alimentar. Ao longo de sua existência, desde a década de 1950, sofreu várias reformulações importantes, frente aos problemas nutricionais enfrentados no país (fome, desnutrição e obesidade). Inicialmente de caráter assistencialista, o objetivo principal era o combate à desnutrição e à evasão escolar ${ }^{5}$.

Atualmente é regulamentado pela Lei $\mathrm{n}^{\circ}$ 11.947 , de 16 de junho de $2009^{6}$ e pela resolução $n^{\circ} 26$, de 17 de junho de $2013^{7}$, do Fundo Nacional de Desenvolvimento e Educação (FNDE), órgão responsável pelo gerenciamento do programa. O PNAE busca garantir a todos os estudantes matriculados em escolas públicas e entidades filantrópicas uma alimentação adequada e saudável. Tem como objetivo contribuir para o crescimento, o desenvolvimento biopsicossocial, a aprendizagem, o rendimento escolar e a formação de hábitos alimentares saudáveis, por meio de ações de educação alimentar e nutricional e da oferta de refeições que cubram parte das necessidades nutricionais dos estudantes durante o período letivo ${ }^{6}$.

No ano de 2014, o governo federal brasileiro contou com um orçamento de 3,6 milhões de reais para atender os 42,2 milhões de estudantes do ensino infantil, fundamental, médio e educação de jovens e adultos. Esse valor ainda é complementado obrigatoriamente com recursos próprios de cada município ou estado (entidades executoras).

Nos EUA, o programa denominado National School Lunch Program (NSLP) fornece a AE a estudantes de escolas públicas e privadas sem fins lucrativos desde o ano de 1946, com a publicação do National School Lunch Act ${ }^{9}$. O objetivo inicial era garantir a saúde e o bem-estar das crianças americanas e incentivar o consumo interno de commodities agrícolas (produtos in natura) e outros alimentos saudáveis ${ }^{10}$.

O NSLP atualmente é administrado em nível federal pelo Serviço de Alimentação e Nutrição do United States Department of Agriculture (USDA), e em nível local pelas agências educacionais estatais. As escolas que participam do programa recebem reembolso financeiro pelas refeições servidas que atendem às regulamentações federais. Embora as escolas não sejam obrigadas a participar do NSLP, $94 \%$ delas o fazem ${ }^{10}$.

A oferta de refeições pelas escolas pode ser gratuita ou com preço reduzido, de acordo com a renda familiar que é o critério de elegibilidade dos alunos. Aqueles que não são elegíveis ao benefício podem participar mediante pagamento, que no período de 2009/2010 era em torno de US\$1,93. A refeição com preço reduzido aos 
alunos elegíveis não pode ultrapassar US\$ $0,40^{11}$.

O NSLP atendeu no ano de $2012 \mathrm{em}$ torno de 31,6 milhões de alunos, sendo que $65 \%$ das refeições foram servidas gratuitamente ou com preço reduzido, e foi desembolsada pelo governo federal a quantia de US $\$ 11,6$ bilhões ${ }^{11,12}$.

Tendo em vista a magnitude e a importância dos programas de alimentação escolar e do ambiente escolar como promotor de práticas saudáveis de alimentação e nutrição, visando à garantia de SAN para a população dos escolares, o consumo da AE constitui um fator primordial nesse contexto. Diante disso, este estudo apresenta uma revisão com o objetivo de identificar os principais fatores que influenciam a adesão e a aceitação da alimentação escolar entre estudantes brasileiros e americanos, apontando as diferenças entre os programas de alimentação escolar do Brasil e dos EUA.

\section{Métodos}

Trata-se de uma revisão integrativa elaborada conforme as etapas apontadas pela literatura: elaboração da questão de pesquisa, estabelecimento de critérios de inclusão e exclusão para amostragem, coleta dos dados através de um instrumento para sintetizar as informações, analise crítica dos estudos selecionados, discussão dos resultados e a apresentação da revisão ${ }^{13}$.

O período de coleta de dados ocorreu entre os meses de julho e agosto de 2015 e os trabalhos científicos foram selecionados nas seguintes bases de dados: Literatura Latino - Americana e do Caribe em Ciências da Saúde (Lilacs), Scientific Eletronic Library Online (SciELO), Pubmed, e Science Direct, utilizando os seguintes descritores em português e inglês: "adesão à alimentação escolar" (adherence of school feeding), "aceitação à alimentação escolar" (accepting of school feeding), "Programa Nacional de Alimentação Escolar" e National School Lunch Program.

As questões norteadoras dessa pesquisa foram: "Quais são os principais fatores que influenciam na adesão e na aceitação da alimentação escolar no Brasil e nos EUA?" "Quais as principais diferenças entre o PNAE e o NSLP?"

Os artigos foram selecionados com base nos seguintes critérios de inclusão: publicações a partir do ano 2000; texto completo para o acesso; idiomas em inglês, português e espanhol; que apresentassem como foco do estudo a investigação de fatores que influenciam o consumo da alimentação escolar nos níveis de ensino brasilei- ro fundamental e médio e seus correspondentes para educação americana (elementary, middle e high school). Foram excluídos artigos de revisão, artigos de abordagem qualitativa, teses, dissertações e monografias; artigos referentes a ensino infantil e pré-escolar; que abordassem outras avaliações sobre o PNAE e NSLP e que fossem referentes a outros programas que fornecem alimentos ou refeições nas escolas.

Dos estudos selecionados foram coletados os dados de interesse para análise por meio de um instrumento de coleta que abrange publicação (título, autor, ano, revista), amostra, objetivos, a metodologia empregada, resultados e conclusões de cada estudo, sendo que os principais dados foram sistematizados em quadros apresentados na seção dos resultados.

A fim de identificar as características estruturais de cada programa também foi realizada uma busca nos sites eletrônicos dos órgãos responsáveis pelo gerenciamento em cada país - FNDE e USDA - para a seleção das regulamentações oficiais.

A análise dos dados foi realizada de forma descritiva e comparativa, e resultou na construção de categorias de fatores que influenciam no consumo da alimentação escolar no Brasil e nos EUA, de acordo com as características estruturais de ambas as políticas.

\section{Resultados e Discussão}

Inicialmente foram encontrados 31.040 artigos, sendo que $240(0,8 \%)$ estavam indexados na base de dados Lilacs, $72(0,2 \%)$ na base SciELO, 337 $(1,0 \%)$ na base Pubmed e 30.391 (98\%) na base Science Direct. O processo de seleção dos artigos procedeu conforme Figura 1.

Quanto aos artigos relativos ao PNAE (Quadro 1), observou-se o baixo número de publicações referentes à adesão e aceitação da $\mathrm{AE}$ e que investigassem, especialmente, os fatores relacionados utilizando metodologia estatística de associação $(42,8 \%)^{14-16}$. Avaliando-se a qualidade das revistas em que os estudos foram publicados de acordo com a classificação de periódicos Qualis/ Capes (área da Nutrição), verificou-se que não havia nenhuma publicação em estrato A1 e A2, sendo que $28,6 \%$ das publicações pertenciam ao estrato $\mathrm{B} 1^{14,17}, 28,6 \%$ ao $\mathrm{B} 2^{16,18} \mathrm{e}$ as demais aos estratos B3 e B4 $(42,9 \%)^{15,19,20}$. Não foi encontrada nenhuma publicação na região Norte e Centro -Oeste e a maioria dos estudos avaliados estava concentrada na região Sudeste $(42,9 \%)^{16,18,19}$, 


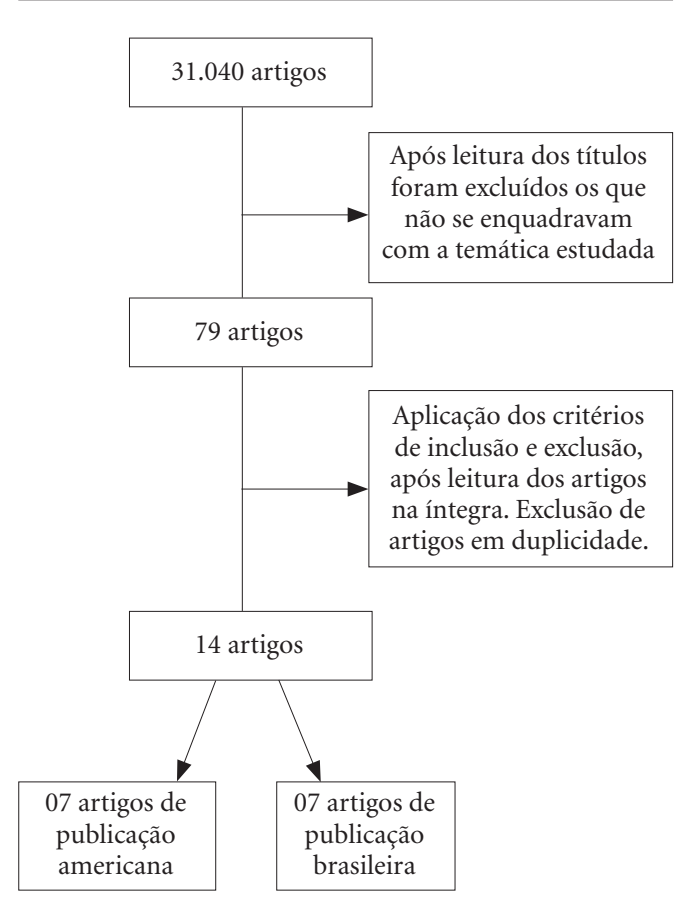

Figura 1. Fluxograma de seleção dos artigos incluídos no estudo.

seguida pela região Sul $(28,6 \%)^{15,20}$, região Nordeste $(14,3 \%)^{17}$ e uma publicação de amostragem nacional $(14,3 \%)^{14}$.

No Quadro 2 são apresentadas as publicações referentes ao NSLP. Pode-se verificar também o baixo número de estudos publicados nos EUA. Contudo, as revistas em que as publicações foram veiculadas apresentam melhor classificação Qualis/Capes, quando comparadas com os estudos publicados do Brasil, sendo que 57,1\% dos estudos nos EUA foram publicados em revistas do estrato $\mathrm{A}^{21-24}$ e 42,9\% nos estratos $\mathrm{A} 2$ e $\mathrm{B} 1^{25-27}$. Dentre esses estudos, 28,6\% são de amostragem nacional ${ }^{24,26}$.

Em relação aos documentos oficiais, foram selecionadas as regulamentações vigentes de cada programa: Lei ${ }^{\circ} 11.947$, de $2009^{6}$, e a Resolução FNDE n 26, de $2013^{7}$, para o Brasil. Para o EUA foram selecionadas a Lei do ano de 1946 - Richard B. Russell National School Lunch Act of $1946^{9}$, o Registro Federal no 17, de 26 de janeiro de 2012 - Nutrition Standards in the National School Lunch and School Breakfast Programs ${ }^{28}$ e a Healthy, Hunger-Free Kids Act of $2010^{29}$.

\section{Adesão e aceitação da alimentação escolar no Brasil: PNAE}

Já evidenciado o baixo número de artigos encontrados por essa revisão, observa-se como limitação a diferença no desenho metodológico entre os estudos, dificultando comparações. Para tanto, foram analisados separadamente os termos "adesão" e "aceitação" aqui considerados. Adesão à alimentação escolar corresponde à medida percentual de alunos que referiram consumir a alimentação fornecida pela escola ${ }^{30}$. Sendo que a adesão efetiva foi considerada por alguns autores como o consumo da $\mathrm{AE}$ de 4 a 5 vezes na semana ${ }^{14,16}$. Para cálculo desse índice, todos os estudos brasileiros utilizaram questionário de avaliação do consumo da $\mathrm{AE}$ aplicado aos alunos, exceto Hernández et al. ${ }^{15}$ que adotaram recordatório 24 horas como estratégia metodológica. Foi verificado que embora o PNAE seja de caráter universal, destinado a todos os estudantes matriculados na rede pública de educação básica, apenas uma parcela consome efetivamente a $\mathrm{AE}$ $(33,5 \% \text { a } 46 \%)^{14,17}$.

Dentre os vários fatores elencados como determinantes da adesão à $\mathrm{AE}$, destaca-se como mais relevantes as variáveis socioeconômicas, estado nutricional, idade, presença de cantina comercial nas escolas e desenvolvimento de atividades de educação nutricional, considerando apenas os resultados de estudos com análises estatísticas de associação entre variáveis ${ }^{14-16}$.

Segundo Sturion et al. ${ }^{14}$, o PNAE tem grande importância para estudantes de famílias de baixa renda, visto que as variáveis socioeconômicas estavam fortemente associadas à participação e a frequência semanal de consumo da AE. Verificou-se que com o aumento da renda familiar per capita e do nível de escolaridade da mãe diminuiu o percentual de alunos que referiram participar e que consumiam a AE com maior frequência. Aliado a esses resultados, o estudo de Barros et al. ${ }^{19}$ apontou que a maioria dos alunos que apresentava algum nível de insegurança alimentar consumia a AE. A insegurança alimentar diagnosticada pela Escala Brasileira de Insegurança Alimentar (EBIA) reflete as dificuldades de acesso aos alimentos em quantidade e qualidade suficientes, sendo decorrente, dentre outras dimensões, das questões sociais e econômicas familiares $^{31}$.

No final da década de 1980, o estudo mais antigo publicado sobre a adesão à alimentação escolar, a Pesquisa Nacional de Saúde e Nutrição $(\mathrm{PNSN})^{32}$, também já apontava essa relação. Cabe 
Quadro 1. Estudos que avaliaram a adesão e a aceitação à alimentação escolar (AE) no Brasil.

\begin{tabular}{|c|c|c|c|c|c|}
\hline $\begin{array}{c}\text { Autor, } \\
\text { ano de } \\
\text { publicação } \\
\text { e local de } \\
\text { estudo }\end{array}$ & $\begin{array}{c}\text { Amostra e } \\
\text { abrangência } \\
\text { do estudo }\end{array}$ & Objetivos & $\begin{array}{c}\text { Metodologia/ } \\
\text { Análises } \\
\text { Estatísticas }\end{array}$ & Principais resultados & Conclusões \\
\hline $\begin{array}{l}\text { Flávio et } \\
\text { al. (2004), } \\
\text { Lavras } \\
(\mathrm{MG})^{18}\end{array}$ & $\begin{array}{l}598 \text { alunos } \\
\text { de uma } \\
\text { escola da } \\
\text { rede pública } \\
\text { estadual, } \\
\text { ensino } \\
\text { fundamental. }\end{array}$ & $\begin{array}{l}\text { Analisar a } \\
\text { composição } \\
\text { química e } \\
\text { realizar a } \\
\text { pesquisa sobre } \\
\text { a aceitação da } \\
\text { AE. }\end{array}$ & $\begin{array}{l}\text { Questionário } \\
\text { de avaliação } \\
\text { do consumo, } \\
\text { preferências e } \\
\text { aceitação da AE. } \\
\text { Análise descritiva. }\end{array}$ & $\begin{array}{l}\text { Entre os alunos, } 72 \% \text { tinham o hábito } \\
\text { de consumir a AE, porém apenas } \\
25 \% \text { consumiam diariamente e } \\
16 \% \text { não consumiam nenhum dia. } \\
\text { Arroz temperado com carne moída, } \\
\text { arroz doce e macarronada com } \\
\text { carne moída obtiveram } 90 \%, 70 \% \\
\text { e } 67 \% \text { de percentual de aceitação, } \\
\text { respectivamente. A sopa de farinha } \\
\text { de milho com ovos e couve foi a } \\
\text { que obteve o menor percentual de } \\
\text { aceitação (27\%), seguida do tutu de } \\
\text { feijão com ovos e couve ( } 30 \%) \text {. }\end{array}$ & $\begin{array}{l}\text { Baixo índice de } \\
\text { adesão efetiva. A } \\
\text { aceitação da AE foi } \\
\text { satisfatória. Cardápios } \\
\text { que possuíam } \\
\text { o arroz como } \\
\text { ingrediente básico } \\
\text { apresentaram os } \\
\text { maiores percentuais } \\
\text { de aceitação. }\end{array}$ \\
\hline $\begin{array}{l}\text { Sturion et } \\
\text { al. (2005, } 10 \\
\text { municípios } \\
\text { brasileiros }^{14}\end{array}$ & $\begin{array}{l}2678 \text { alunos } \\
\text { de } 20 \text { escolas } \\
\text { da rede } \\
\text { pública, } \\
\text { ensino } \\
\text { fundamental. }\end{array}$ & $\begin{array}{l}\text { Verificar } \\
\text { o nível de } \\
\text { adesão dos } \\
\text { alunos ao } \\
\text { PNAE e } \\
\text { identificar } \\
\text { as principais } \\
\text { variáveis que a } \\
\text { afetam. }\end{array}$ & $\begin{array}{l}\text { Questionário } \\
\text { de avaliação do } \\
\text { consumo da } \\
\text { AE, avaliação } \\
\text { antropométrica } \\
\text { e perfil } \\
\text { socioeconômico. } \\
\text { Teste do } \chi^{2} \text {, teste } \\
\text { do } \chi^{2} \text { de tendência } \\
\text { linear de Mantel- } \\
\text { Haensze e modelo } \\
\text { de lógite. Valor p }< \\
0,001 \text { e }<0,005 .\end{array}$ & $\begin{array}{l}\text { A adesão efetiva foi de } 46 \% \text {.As } \\
\text { variáveis de renda familiar per capita } \\
(\beta 0,0021, p<0,0001) \text {, escolaridade } \\
\text { do pai }(\beta 0,0402, p<0,0277) \text {, idade }(\beta \\
0,0043, p<0,0474) \text { e estado nutricional } \\
(\beta 0,0068, p<0,0003) \text { foram associadas } \\
\text { a "frequência semanal de consumo da } \\
\text { alimentação escolar". A renda familiar } \\
\text { per capita ( } \beta \text { - } 0,0032, p<0,0001), \\
\text { a escolaridade do pai ( } \beta \text {-0,0959, } \\
\text { p< } 0,0001) \text { e a idade }(\beta-0,0155, \\
\text { p }<0,0001) \text { também foram associadas } \\
\text { inversamente com a variável } \\
\text { "participação do aluno no programa". } \\
\text { Nas escolas com presença de cantina } \\
\text { comercial, a maior frequência } \\
\text { semanal de consumo de alimentos na } \\
\text { cantina foi associada negativamente a } \\
\text { "participação do aluno no programa" } \\
(\beta 0,5455, p<0,0001) \text { e a "frequência } \\
\text { semanal de consumo da alimentação } \\
\text { escolar" ( } \beta-0,4357, p<0,0013) \text {. }\end{array}$ & $\begin{array}{l}\text { A adesão à AE foi } \\
\text { baixa e fortemente } \\
\text { afetada pelas variáveis } \\
\text { socioeconômicas, } \\
\text { idade e estado } \\
\text { nutricional dos } \\
\text { alunos. Nas escolas } \\
\text { que não há presença } \\
\text { de cantina comercial, } \\
\text { a frequência do } \\
\text { consumo da } \\
\text { alimentação escolar } \\
\text { foi maior. }\end{array}$ \\
\hline $\begin{array}{l}\text { Muniz e } \\
\text { Carvalho } \\
(2007) \text {, } \\
\text { João Pessoa } \\
(\text { PB })^{17}\end{array}$ & $\begin{array}{l}240 \text { alunos de } \\
10 \text { escolas da } \\
\text { rede pública } \\
\text { municipal, } \\
\text { ensino } \\
\text { fundamental. }\end{array}$ & $\begin{array}{l}\text { Analisar a } \\
\text { adesão e a } \\
\text { aceitação da } \\
\text { alimentação } \\
\text { escolar e seus } \\
\text { determinantes } \\
\text { sob o ponto } \\
\text { de vista dos } \\
\text { beneficiários } \\
\text { do PNAE. }\end{array}$ & $\begin{array}{l}\text { Questionário } \\
\text { de avaliação do } \\
\text { consumo da AE. } \\
\text { Considerou índice } \\
\text { de aceitação } \\
\text { o percentual } \\
\text { de alunos que } \\
\text { referiram gostar } \\
\text { da AE. Análise } \\
\text { descritiva e teste } \\
\text { 2. As questões } \\
\text { abertas foram } \\
\text { categorizadas a } \\
\text { partir do conceito } \\
\text { central contido nas } \\
\text { respostas. }\end{array}$ & $\begin{array}{l}\text { A adesão efetiva foi de } 33,5 \% \text {. O } \\
\text { consumo da AE esporadicamente foi } \\
\text { referido por } 57,3 \% \text { dos estudantes. O } \\
\text { principal motivo para não consumo } \\
\text { permanente da AE foi a inadequação } \\
\text { das preparações aos hábitos } \\
\text { alimentares }(41,5 \%) \text {, seguido dos } \\
\text { que não consomem por estarem sem } \\
\text { apetite, quando levam alimentos de } \\
\text { casa ou quando compram nas escolas } \\
\text { (32,5\%). Dos alunos que consideram } \\
\text { a AE importante (208), a principal } \\
\text { justificativa foi por necessidade } \\
\text { relacionada a dificuldades financeiras } \\
\text { das famílias ou ao fato de sentir fome } \\
\text { na escola (41\%). O índice de aceitação } \\
\text { foi de } 82 \%, \text { sendo que a grande } \\
\text { maioria (76,7\%) relatou gostar da AE } \\
\text { por ser saborosa. }\end{array}$ & $\begin{array}{l}\text { Concluiu-se avaliação } \\
\text { positiva dos escolares } \\
\text { quanto a AE. O sabor } \\
\text { das preparações e } \\
\text { a adequação dos } \\
\text { cardápios parecem } \\
\text { exercer influência } \\
\text { na participação no } \\
\text { programa. }\end{array}$ \\
\hline
\end{tabular}


Quadro 1. continuação

\begin{tabular}{|c|c|c|c|c|c|}
\hline $\begin{array}{c}\text { Autor, } \\
\text { ano de } \\
\text { publicação } \\
\text { e local de } \\
\text { estudo }\end{array}$ & $\begin{array}{l}\text { Amostra e } \\
\text { abrangência } \\
\text { do estudo }\end{array}$ & Objetivos & $\begin{array}{c}\text { Metodologia/ } \\
\text { Análises } \\
\text { Estatísticas }\end{array}$ & Principais resultados & Conclusões \\
\hline $\begin{array}{l}\text { Hernández } \\
\text { et al. (2008), } \\
\text { Porto Alegre } \\
(\mathrm{RS})^{15}\end{array}$ & $\begin{array}{l}1398 \text { alunos } \\
\text { de quatro } \\
\text { escolas da } \\
\text { rede pública } \\
\text { municipal, } \\
\text { ensino } \\
\text { fundamental. }\end{array}$ & $\begin{array}{l}\text { Descrever os } \\
\text { principais } \\
\text { componentes } \\
\text { da dieta } \\
\text { dos alunos, } \\
\text { verificar } \\
\text { se a AE é } \\
\text { consumida } \\
\text { pelos } \\
\text { estudantes e } \\
\text { se a existência } \\
\text { de cantina } \\
\text { nas escolas } \\
\text { modifica o } \\
\text { consumo da } \\
\text { AE. }\end{array}$ & $\begin{array}{l}\text { Aplicação de um } \\
\text { recordatório } 24 \\
\text { horas. AE era } \\
\text { fornecida pelas } \\
\text { escolas na forma } \\
\text { de bufê, logo se } \\
\text { considerou como } \\
\text { consumo completo } \\
\text { quando todas } \\
\text { as variedades } \\
\text { oferecidas } \\
\text { tiveram seus } \\
\text { consumos citados } \\
\text { pelos alunos. } \\
\text { Análise descritiva e } \\
\text { teste do } \chi^{2} \text {. }\end{array}$ & $\begin{array}{l}\text { O índice de adesão foi de } 41,8 \% \text {. O } \\
\text { consumo completo do lanche e da } \\
\text { refeição foi de } 2,6 \% \text { e } 23,2 \% \text { dos } \\
\text { estudantes afirmaram ter consumido } \\
\text { apenas alimentos fornecidos pela } \\
\text { escola enquanto que } 25,2 \% \text { relataram } \\
\text { não consumir nada no ambiente } \\
\text { escolar. Entre os alunos, } 18,6 \% \\
\text { consumiram tanto os itens oferecidos } \\
\text { pela escola quanto os externos a ela } \\
\text { e } 33 \% \text { ingeriram apenas produtos } \\
\text { alheios à AE. O consumo de alimentos } \\
\text { externos interferiu no consumo da AE } \\
\text { (OR } 1,64, \text { p }<0,01) \text {. }\end{array}$ & $\begin{array}{l}\text { A maioria dos } \\
\text { estudantes não } \\
\text { consome a AE } \\
(58,2 \%) \text {. O consumo } \\
\text { de itens externos no } \\
\text { ambiente escolar deve } \\
\text { ser considerado um } \\
\text { fator que colabora } \\
\text { com o não consumo } \\
\text { da AE. }\end{array}$ \\
\hline $\begin{array}{l}\text { Teo et al. } \\
(2009), \\
\text { Chapecó } \\
(\text { SC })^{20}\end{array}$ & $\begin{array}{l}686 \text { alunos de } \\
21 \text { escolas da } \\
\text { rede pública } \\
\text { municipal } \\
\text { e estadual, } \\
\text { ensino } \\
\text { fundamental. }\end{array}$ & $\begin{array}{l}\text { Conhecer a } \\
\text { aceitação e a } \\
\text { adesão dos } \\
\text { escolares ao } \\
\text { programa, } \\
\text { identificando } \\
\text { quais } \\
\text { aspectos das } \\
\text { condições de } \\
\text { distribuição } \\
\text { de } \\
\text { alimentação } \\
\text { representam } \\
\text { potenciais } \\
\text { determinantes } \\
\text { da sua eficácia. }\end{array}$ & $\begin{array}{l}\text { Questionário } \\
\text { de avaliação } \\
\text { do consumo } \\
\text { da AE e escala } \\
\text { hedônica facial. } \\
\text { Considerou-se } \\
\text { índice de aceitação } \\
\text { o percentual } \\
\text { de alunos que } \\
\text { referiram gostar da } \\
\text { AE. Formulário de } \\
\text { avaliação baseado } \\
\text { na observação } \\
\text { do ambiente } \\
\text { físico e social de } \\
\text { distribuição das } \\
\text { refeições. Análise } \\
\text { descritiva, teste } \\
\text { t-student, teste } \\
\text { do } \chi^{2} \text { de Pearson. } \\
\text { Valor de p < } 0,05 .\end{array}$ & $\begin{array}{l}\text { Entre os alunos } 23,2 \% \text { consumiam } \\
\text { a AE diariamente, sendo maior o } \\
\text { percentual na rede municipal }(29,5 \%) \\
\text { que na estadual }(16,5 \%)(\mathrm{p}<0,001) \text { e } \\
70,8 \% \text { considerou boa a AE. Quanto } \\
\text { às escolas } 76,2 \% \text { distribuíam a AE } \\
\text { em local coberto improvisado, sendo } \\
\text { que } 52,4 \% \text { dos alunos comiam em } \\
\text { pé enquanto circulavam pela escola. } \\
\text { Nas escolas em que era feita a escala } \\
\text { das turmas para a distribuição da } \\
\text { alimentação, a quantidade de mesas e } \\
\text { cadeiras tornava-se suficiente ( } 47,6 \%) \text {. } \\
\text { Entre elas 52,3\% apresentavam } \\
\text { comércio de alimentos e todos os } \\
\text { casos estavam em desacordo com a } \\
\text { legislação vigente no estado. }\end{array}$ & $\begin{array}{l}\text { Baixa adesão diária } \\
\text { à AE. Não foram } \\
\text { pesquisados os } \\
\text { motivos para não } \\
\text { adesão, porém } \\
\text { sugere-se que } \\
\text { condições de } \\
\text { distribuição da } \\
\text { AE (refeitórios, } \\
\text { utensílios, horário) e } \\
\text { presença de cantinas } \\
\text { comerciais possam } \\
\text { estar relacionadas. }\end{array}$ \\
\hline $\begin{array}{l}\text { Barros et } \\
\text { al. (2013), } \\
\text { Carmo } \\
(\mathrm{RJ})^{19}\end{array}$ & $\begin{array}{l}121 \text { alunos } \\
\text { de sete } \\
\text { escolas da } \\
\text { rede pública } \\
\text { municipal, } \\
\text { ensino } \\
\text { fundamental. }\end{array}$ & $\begin{array}{l}\text { Avaliar a } \\
\text { composição } \\
\text { nutricional e a } \\
\text { aceitabilidade } \\
\text { da AE, } \\
\text { o estado } \\
\text { nutricional e } \\
\text { a segurança } \\
\text { alimentar dos } \\
\text { escolares. }\end{array}$ & $\begin{array}{l}\text { Questionário de } \\
\text { aceitabilidade } \\
\text { com questões } \\
\text { de preferências } \\
\text { alimentares e a } \\
\text { Escala Brasileira } \\
\text { de Insegurança } \\
\text { Alimentar e } \\
\text { Nutricional } \\
\text { (EBIA). Análise } \\
\text { descritiva. }\end{array}$ & $\begin{array}{l}\text { A adesão foi de } 88,4 \% \text { dos estudantes, } \\
\text { porém apenas } 34,6 \% \text { consumiam } \\
\text { todos os dias na escola, sendo que a } \\
\text { maioria relatou não gostar de todas } \\
\text { as preparações. A aceitação foi de } \\
85,5 \% \text {. A maioria dos alunos ( } 92 \%) \\
\text { que apresentaram algum nível de } \\
\text { insegurança alimentar consumia a AE. }\end{array}$ & $\begin{array}{l}\text { Baixa adesão diária } \\
\text { a AE. Sugere-se } \\
\text { que a insegurança } \\
\text { alimentar esteja } \\
\text { relacionada ao } \\
\text { consumo da AE. }\end{array}$ \\
\hline
\end{tabular}

ressaltar que, na época dessa pesquisa, o programa era administrado de maneira centralizada e havia muitas falhas no gerenciamento que com- prometiam a qualidade da AE, podendo influenciar a adesão dos alunos. Contudo, tal pesquisa apontou que das 24 milhões de crianças de esco- 
Quadro 1. continuação

\begin{tabular}{|c|c|c|c|c|c|}
\hline $\begin{array}{c}\text { Autor, } \\
\text { ano de } \\
\text { publicação } \\
\text { e local de } \\
\text { estudo }\end{array}$ & $\begin{array}{c}\text { Amostra e } \\
\text { abrangência } \\
\text { do estudo }\end{array}$ & Objetivos & $\begin{array}{l}\text { Metodologia/ } \\
\text { Análises } \\
\text { Estatísticas }\end{array}$ & Principais resultados & Conclusões \\
\hline $\begin{array}{l}\text { Silva et al. } \\
\text { (2013), } \\
\text { Minas } \\
\text { Gerais }^{16}\end{array}$ & $\begin{array}{l}1550 \text { alunos } \\
\text { de } 46 \text { escolas } \\
\text { da rede } \\
\text { pública } \\
\text { estadual, } \\
\text { ensino } \\
\text { fundamental, } \\
\text { médio e } \\
\text { educação } \\
\text { de jovens e } \\
\text { adultos. }\end{array}$ & $\begin{array}{l}\text { Analisar } \\
\text { o PNAE } \\
\text { sob a ótica } \\
\text { dos alunos } \\
\text { atendidos na } \\
\text { rede estadual } \\
\text { de ensino. }\end{array}$ & $\begin{array}{l}\text { Questionários } \\
\text { com perguntas } \\
\text { sobre o consumo } \\
\text { no ambiente } \\
\text { escolar, realização } \\
\text { de atividades de } \\
\text { educação alimentar } \\
\text { e nutricional } \\
\text { (EAN), adequação } \\
\text { do espaço físico } \\
\text { para o consumo } \\
\text { da AE e percepção } \\
\text { do aluno quanto à } \\
\text { qualidade da AE. } \\
\text { A efetiva aceitação } \\
\text { foi considerada } \\
\text { as referências: } \\
\text { "Ótima" ou "Muito } \\
\text { Boa”. Análise } \\
\text { descritiva, teste do } \\
2 \text { de Pearson ou de } \\
\text { Fisher, regressão } \\
\text { logística com valor } \\
\text { de p < } 0,05 \text {. }\end{array}$ & $\begin{array}{l}\text { Entre os estudantes } 28,8 \% \\
\text { apresentaram efetiva aceitação e } \\
45,1 \% \text { efetiva adesão ao programa. } \\
\text { Meninos apresentaram chance } 1,35 \\
\text { vezes maior de aceitação da AE } \\
\text { quando comparados às meninas, } \\
\text { os alunos mais velhos (a partir de } \\
15 \text { anos) apresentaram chance de } \\
\text { aceitação da AE } 1,31 \text { vezes maior } \\
\text { que os mais jovens, alunos que } \\
\text { não compram alimentos extra } \\
\text { institucionais apresentaram o dobro } \\
\text { de chance de aceitação da AE e aqueles } \\
\text { que participam EAN apresentaram } \\
\text { aceitação } 1,87 \text { vezes maior da AE. Em } \\
\text { relação à adesão à AE, os alunos que } \\
\text { participam de alguma atividade de } \\
\text { EAN, apresentaram uma chance de } \\
\text { adesão } 1,39 \text { vezes maior e os alunos } \\
\text { mais velhos (a partir de } 15 \text { anos) } \\
\text { apresentaram uma chance } 1,63 \text { vezes } \\
\text { de maior de adesão. }\end{array}$ & $\begin{array}{l}\text { Baixo índice de } \\
\text { adesão e aceitação } \\
\text { efetiva. Gênero, idade, } \\
\text { atividades de EAN e } \\
\text { cantinas comerciais } \\
\text { estão relacionados } \\
\text { à adesão e aceitação } \\
\text { a AE. }\end{array}$ \\
\hline
\end{tabular}

las públicas matriculadas no ensino de primeiro grau, em 1989, 19 milhões frequentavam escolas que ofereciam alimentação escolar. Dentre elas, apenas $41 \%$ consumiam diariamente, sendo que era menor a adesão à medida que aumentava a renda domiciliar per capita das famílias. De acordo com a PNSN (1989), as crianças em situações de risco nutricional tinham menos acesso a escolas que ofereciam alimentação escolar em relação às crianças de menor vulnerabilidade social ${ }^{32}$.

Ainda, Hoffman ${ }^{5}$, ao buscar os fatores associados ao consumo da alimentação escolar, analisando os dados da Pesquisa Nacional por Amostra por domicílios (PNAD), entre 2004 e 2006, evidenciou que quanto menor a renda familiar e idade do escolar, maior é o consumo da alimentação escolar, concluindo que o programa acaba sendo direcionado aos alunos mais novos e mais pobres.

O PNAE, no início de sua trajetória, era um programa social com caráter assistencialista, voltado às questões de fome e pobreza enfrentadas pelo país, com objetivo de reduzir a desnutrição e a evasão escolar ${ }^{5}$. Atualmente, mesmo com as mudanças ocorridas em seus objetivos, muitas pessoas ainda apontam o programa como voltado apenas para crianças carentes que têm na $\mathrm{AE}$ sua principal refeição ${ }^{33}$. O programa é o único com atendimento universalizado, e para que seus objetivos sejam atendidos - crescimento, desenvolvimento, aprendizagem, rendimento escolar e formação de hábitos alimentares - o consumo da AE por todos os alunos é premissa básica.

Em relação à variável idade, observa-se que os dados apresentados são controversos, à medida que se identifica forte associação inversa (quanto menor idade, maior participação no programa $)^{14}$, como também associação direta (maior participação entre os estudantes mais velhos ${ }^{16}$. No entanto, pode-se observar que os fatores condicionantes à adesão podem ser diferentes de acordo com a idade dos estudantes. Sturion et al. ${ }^{14}$ investigaram estudantes mais novos, com idade entre 07 a 14 anos, que evidenciaram forte influência de fatores socioeconômicos e de estado nutricional. Entre os estudantes mais velhos, 
Quadro 2. Estudos que avaliaram a aceitação e adesão à alimentação escolar (AE) nos EUA

\begin{tabular}{|c|c|c|c|c|c|}
\hline $\begin{array}{l}\text { Autor, ano de } \\
\text { publicação } \\
\text { e local do } \\
\text { estudo }\end{array}$ & $\begin{array}{l}\text { Amostra e } \\
\text { abrangência } \\
\text { do estudo }\end{array}$ & Objetivos & $\begin{array}{c}\text { Metodologia/ } \\
\text { Análises } \\
\text { Estatísticas }\end{array}$ & Principais resultados & Conclusões \\
\hline $\begin{array}{l}\text { Marlette et } \\
\text { al. (2005), } \\
\text { Frankfort } \\
(\text { Kentucky) })^{21}\end{array}$ & $\begin{array}{l}743 \text { alunos } \\
\text { de } 3 \text { escolas } \\
\text { de ensino } \\
\text { fundamental } \\
\text { (Middle } \\
\text { School). }\end{array}$ & $\begin{array}{l}\text { Determinar } \\
\text { os fatores que } \\
\text { influenciam } \\
\text { o desperdício } \\
\text { e a aceitação } \\
\text { das refeições } \\
\text { escolares. }\end{array}$ & $\begin{array}{l}\text { Pesagem das sobras } \\
\text { das refeições (plate } \\
\text { waste). Teste do } \chi^{2} \text {, } \\
\text { análise de variância } \\
\text { e modelos de } \\
\text { regressão. }\end{array}$ & $\begin{array}{l}\text { Maçãs inteiras tiveram aceitação mais } \\
\text { baixa }(23 \%) \text { e maior desperdício } \\
(62 \%) \text { em comparação com compota } \\
\text { de maçã ( } 37 \% \text { de aceitação e } 23 \% \text { de } \\
\text { desperdício). Purê de batatas e batatas } \\
\text { fritas tiveram aceitação semelhante } \\
\text { (aproximadamente } 69 \%) \text {, mas purê } \\
\text { de batatas foi menos desperdiçado } \\
\text { (19\% e } 33 \% \text {, respectivamente). } \\
\text { Alunos que compraram alimentos } \\
\text { competitivos juntamente com a AE } \\
\text { tiveram taxas significativamente } \\
\text { maiores de desperdícios para frutas } \\
(52,3 \% \pm 3,7) \text { grãos }(21,5 \% \pm 2,6), \\
\text { carnes }(25,3 \% \pm 3,2) \text { e pratos mistos } \\
(29,8 \% \pm 2,9) \text { (p<0,05) }\end{array}$ & $\begin{array}{l}\text { Aceitação e } \\
\text { desperdício } \\
\text { de alimentos } \\
\text { diferem por } \\
\text { tipo de alimento } \\
\text { e método de } \\
\text { preparação. } \\
\text { Disponibilidades } \\
\text { de alimentos } \\
\text { competitivos } \\
\text { influenciam } \\
\text { na taxa de } \\
\text { desperdício da } \\
\text { AE. }\end{array}$ \\
\hline $\begin{array}{l}\text { Probart et } \\
\text { al. (2006), } \\
\text { Pensilvânia }^{22}\end{array}$ & $\begin{array}{l}228 \text { escolas de } \\
\text { ensino médio } \\
\text { (High school). }\end{array}$ & $\begin{array}{l}\text { Identificar } \\
\text { fatores } \\
\text { preditores da } \\
\text { oferta e venda } \\
\text { de alimentos } \\
\text { competitivos } \\
\text { em ambiente } \\
\text { escolar, e da } \\
\text { participação } \\
\text { média diária } \\
\text { na AE. }\end{array}$ & $\begin{array}{l}\text { Questionário para } \\
\text { os responsáveis } \\
\text { pelos serviços } \\
\text { de alimentação } \\
\text { das escolas. } \\
\text { Identificação de } \\
\text { pontos de vendas } \\
\text { de alimentos } \\
\text { competitivos } \\
\text { ( } \text { la carte e } \\
\text { máquinas de } \\
\text { venda automática). } \\
\text { Regressão linear } \\
\text { múltipla. }\end{array}$ & $\begin{array}{l}\text { A média da participação diária } \\
\text { no programa de AE foi de } \\
56,5 \% \pm 18,5 \% \text {. Escolas com maior } \\
\text { número de matriculados tiveram } \\
\text { menor participação média diária no } \\
\text { programa do que escolas menores } \\
(\beta-0,277, \mathrm{p}<0,001) \text {. Escolas com } \\
\text { maior porcentagem de alunos } \\
\text { elegíveis a preço reduzido ou gratuito } \\
\text { apresentaram maiores níveis de } \\
\text { participação }(\beta 0,207, \mathrm{p}<0,002) \text {. } \\
\text { A presença de regulamentação que } \\
\text { proíbe que pais/alunos tragam } \\
\text { alimentos competitivos }(\text { fast-foods) } \\
\text { para escola também influenciou na } \\
\text { participação no programa }(\beta 0,136, \\
\text { p }<0,04) \text {. Sugeriu-se que anúncios } \\
\text { de refrigerantes no ambiente escolar } \\
\text { influenciaram negativamente na } \\
\text { participação do programa }(\beta-0,121, p \\
<0,07)\end{array}$ & $\begin{array}{l}\text { Tamanho das } \\
\text { escolas, taxa de } \\
\text { elegibilidade a } \\
\text { preço reduzido } \\
\text { ou gratuito, } \\
\text { regulamentação } \\
\text { de alimentos } \\
\text { competitivos no } \\
\text { ambiente escolar } \\
\text { e marketing } \\
\text { desses produtos } \\
\text { influenciam } \\
\text { na adesão ao } \\
\text { programa. }\end{array}$ \\
\hline
\end{tabular}

população do estudo de Silva et al. ${ }^{16}$, a participação em atividades de educação alimentar e nutricional no ambiente escolar foi um fator associado à adesão à $\mathrm{AE}$, sugerindo influência de fatores comportamentais, como a mudança de práticas e escolhas alimentares.

As preferências alimentares e adequação do cardápio parecem exercer influência na participação do programa, como também apontado por Muniz e Carvalho ${ }^{17}$, que encontraram como principal motivo para o consumo esporádico da
AE pelos alunos a inadequação das preparações aos hábitos alimentares. De acordo com a legislação vigente do $\mathrm{PNAE}^{8}$, os cardápios escolares devem atender de $20 \%$ a $30 \%$ das necessidades nutricionais durante o período de permanência do estudante na escola em período parcial, e 70\% para estudantes que permanecem em período integral. Esses cardápios devem ser elaborados tendo por base a cultura e a tradição alimentar de cada região. É preciso avaliar se a preparação que está sendo oferecida faz parte do hábito alimen- 
Quadro 2. continuação

\begin{tabular}{|c|c|c|c|c|c|}
\hline $\begin{array}{l}\text { Autor, ano de } \\
\text { publicação } \\
\text { e local do } \\
\text { estudo }\end{array}$ & $\begin{array}{l}\text { Amostra e } \\
\text { abrangência } \\
\text { do estudo }\end{array}$ & Objetivos & $\begin{array}{l}\text { Metodologia/ } \\
\text { Análises } \\
\text { Estatísticas }\end{array}$ & Principais resultados & Conclusões \\
\hline $\begin{array}{l}\text { Mirtcheva } \\
\text { and Powell } \\
(2009), \text { EUA }^{26}\end{array}$ & $\begin{array}{l}2563 \text { alunos } \\
\text { de escolas } \\
\text { públicas } \\
\text { de ensino } \\
\text { fundamental } \\
\text { e médio } \\
\text { (Middle and } \\
\text { High school). }\end{array}$ & $\begin{array}{l}\text { Examinar } \\
\text { o efeito do } \\
\text { estigma, } \\
\text { características } \\
\text { ambientais e } \\
\text { demográficas } \\
\text { sobre a } \\
\text { participação } \\
\text { no NSLP. }\end{array}$ & $\begin{array}{l}\text { Análise do } \\
\text { banco de dados } \\
\text { de registro da } \\
\text { distribuição das } \\
\text { refeições de } 1997 \text { a } \\
\text { 2003. Modelos de } \\
\text { Regressão. }\end{array}$ & $\begin{array}{l}\text { Entre os alunos } 70 \% \text { participavam do } \\
\text { programa. Um aumento de } 10 \% \text { na } \\
\text { proporção de alunos elegíveis para a } \\
\text { refeição gratuita foi associada a um } \\
\text { aumento de } 1,8 \text { vezes na probabilidade } \\
\text { de participação geral no programa, } \\
\text { um aumento de } 2,6 \text { vezes para todos } \\
\text { os alunos elegíveis a refeição gratuita/ } \\
\text { preço reduzido e } 6,7 \text { vezes para } \\
\text { alunos do ensino médio elegíveis a } \\
\text { refeição gratuita/preço reduzido. Em } \\
\text { comparação com estudantes do ensino } \\
\text { fundamental, os do ensino médio } \\
\text { foram de } 14 \text { e } 20 \% \text { menos propensos } \\
\text { de participar no NSLP a preço livre ou } \\
\text { reduzido, respectivamente. Estudantes } \\
\text { de famílias de renda mais alta eram } \\
\text { menos propensos a participar do } \\
\text { programa. A disponibilidade de } \\
\text { restaurantes de fast food em torno } \\
\text { da escola foi associada com a menor } \\
\text { probabilidade de participar do } \\
\text { programa a preço livre ou reduzido } \\
\text { entre estudantes do ensino médio } \\
\text { (-0,04). }\end{array}$ & $\begin{array}{l}\text { A taxa de } \\
\text { elegibilidade } \\
\text { das escolas para } \\
\text { o programa } \\
\text { gratuito ou a } \\
\text { preço reduzido } \\
\text { está associada } \\
\text { ao consumo da } \\
\text { AE, sugerindo } \\
\text { associação com } \\
\text { a estigmatização } \\
\text { da participação } \\
\text { no programa. } \\
\text { Também existe } \\
\text { associação } \\
\text { negativa entre } \\
\text { disponibilidade } \\
\text { de comércio de } \\
\text { alimentos em } \\
\text { torno da escola e } \\
\text { a participação no } \\
\text { programa. }\end{array}$ \\
\hline $\begin{array}{l}\text { Bhatia et al. } \\
\text { (2011), San } \\
\text { Francisco } \\
\text { (Califórnia) }^{23}\end{array}$ & $\begin{array}{l}3 \text { escolas de } \\
\text { ensino } \\
\text { fundamental } \\
\text { e médio } \\
\text { (Middle and } \\
\text { High school). }\end{array}$ & $\begin{array}{l}\text { Descrever a } \\
\text { intervenção } \\
\text { realizada no } \\
\text { ambiente } \\
\text { escolar e sua } \\
\text { avaliação. }\end{array}$ & $\begin{array}{l}\text { Departamento } \\
\text { de Saúde Pública } \\
\text { de San Francisco } \\
\text { realizou uma } \\
\text { intervenção } \\
\text { com mudanças } \\
\text { no ambiente } \\
\text { escolar (retirada } \\
\text { do serviço de } \\
\text { comércio de } \\
\text { alimentos a la } \\
\text { carte fora do } \\
\text { NSLP, aumento } \\
\text { do número e } \\
\text { diversidade } \\
\text { dos alimentos } \\
\text { do programa, } \\
\text { investimento em } \\
\text { equipamentos e } \\
\text { na formação da } \\
\text { equipe de trabalho, } \\
\text { implantação de } \\
\text { um sistema de } \\
\text { pagamento que } \\
\text { não identifica os } \\
\text { alunos de baixa } \\
\text { renda). Análise } \\
\text { descritiva. }\end{array}$ & $\begin{array}{l}\text { Após intervenção, para os alunos } \\
\text { que se qualificaram para gratuidade } \\
\text { no programa, os aumentos nas } \\
\text { porcentagens de participação foram } \\
\text { de } 13 \% \text { na escola A, } 41 \% \text { na escola B, } \\
\text { e } 73 \% \text { na escola C. Entre os estudantes } \\
\text { que se qualificaram para refeições } \\
\text { a preço reduzido, a participação } \\
\text { aumentou } 23 \%, 38 \% \text { e } 154 \%, \\
\text { respectivamente nas três escolas. A } \\
\text { participação dos estudantes que não se } \\
\text { qualificaram para gratuidade ou preço } \\
\text { reduzido aumentou em apenas em } \\
\text { uma escola. }\end{array}$ & $\begin{array}{l}\text { Alimentos } \\
\text { competitivos } \\
\text { podem interferir } \\
\text { na participação } \\
\text { no NLSP. } \\
\text { A retirada desses } \\
\text { alimentos do } \\
\text { ambiente escolar } \\
\text { pode aumentar } \\
\text { a participação } \\
\text { entre os alunos } \\
\text { de baixa renda, } \\
\text { sendo que esse } \\
\text { efeito pode ser } \\
\text { explicado por } \\
\text { redução da } \\
\text { estigmatização } \\
\text { dos alunos. }\end{array}$ \\
\hline
\end{tabular}


Quadro 2. continuação

\begin{tabular}{|c|c|c|c|c|c|}
\hline $\begin{array}{c}\text { Autor, ano de } \\
\text { publicação } \\
\text { e local do } \\
\text { estudo }\end{array}$ & $\begin{array}{l}\text { Amostra e } \\
\text { abrangência } \\
\text { do estudo }\end{array}$ & Objetivos & $\begin{array}{c}\text { Metodologia/ } \\
\text { Análises } \\
\text { Estatísticas }\end{array}$ & Principais resultados & Conclusões \\
\hline $\begin{array}{l}\text { Hernandez } \\
\text { et al. (2011), } \\
\text { EUA }^{24}\end{array}$ & $\begin{array}{l}1140 \text { alunos } \\
\text { de baixa } \\
\text { renda de } \\
\text { escolas } \\
\text { públicas e } \\
\text { privadas } \\
\text { participantes } \\
\text { do NLSP } \\
\text { do jardim } \\
\text { de infância } \\
\text { e ensino } \\
\text { fundamental } \\
\text { (1a, 3a e } 5^{\text {a }} \\
\text { série). } \\
\text { (Elementary } \\
\text { school). }\end{array}$ & $\begin{array}{l}\text { Identificar a } \\
\text { participação } \\
\text { no NSLP } \\
\text { entre crianças } \\
\text { de baixa } \\
\text { renda e } \\
\text { analisar sua } \\
\text { influência } \\
\text { entre os } \\
\text { gêneros e } \\
\text { evolução } \\
\text { do índice } \\
\text { de massa } \\
\text { corporal. }\end{array}$ & $\begin{array}{l}\text { Estudo de } \\
\text { avaliação } \\
\text { longitudinal com } \\
\text { análise de três } \\
\text { variáveis: nenhuma } \\
\text { participação, } \\
\text { participação } \\
\text { constante (em } \\
\text { todos níveis de } \\
\text { ensino analisados), } \\
\text { participação } \\
\text { transitória (em } \\
\text { alguns níveis } \\
\text { de ensino). } \\
\text { Coleta de dados } \\
\text { sociodemográficos } \\
\text { e de estilo de } \\
\text { vida, avaliação } \\
\text { antropométrica. } \\
\text { Análise descritiva } \\
\text { e modelos de } \\
\text { regressão de } \\
\text { Poisson. }\end{array}$ & $\begin{array}{l}\text { Entre os alunos } 82 \% \text { participaram } \\
\text { do programa em algum momento } \\
\text { do jardim de infância até a } 5^{\circ} \text { série } \\
\text { ( } 35 \% \text { constante e } 47 \% \text { transitória). } \\
\text { Alunos negros não-hispânicos eram } \\
39 \% \text { mais propensos a participação } \\
\text { constante do que crianças brancas } \\
\text { não-hipânicas (p } 0,01 \text { ). Os alunos } \\
\text { hispânicos eram } 79 \% \text { mais propensos } \\
\text { à participação constante do que os } \\
\text { alunos não-hispânicos (p < } 0,001 \text { ). } \\
\text { Os alunos cujas mães não concluíram } \\
\text { o ensino médio eram } 29 \% \text { mais } \\
\text { propensos à participação constante do } \\
\text { que as crianças cujas mães concluíram } \\
\text { o ensino médio (p }<0,001 \text { ). Alunos } \\
\text { que viviam em domicílios com renda } \\
\text { familiar inferior a } 185 \% \text { do nível } \\
\text { federal de pobreza na } 1^{\text {a }, ~} 3^{\text {a }} \text { e } 5^{\mathrm{a}} \text { série } \\
\text { tiveram aproximadamente } 1,5 \text { a } 2 \text { vezes } \\
\text { mais chances do que outras crianças a } \\
\text { participação constante no programa (p } \\
<0,001 \text { ). }\end{array}$ & $\begin{array}{l}\text { Houve } \\
\text { associação entre } \\
\text { características } \\
\text { socioeconômicas } \\
\text { e demográficas } \\
\text { desfavorecidas e } \\
\text { a participação no } \\
\text { NLSP. }\end{array}$ \\
\hline $\begin{array}{l}\text { Ohri- } \\
\text { Vachaspati } \\
(2014) \text {, cinco } \\
\text { cidades de } \\
\text { New Jersey }\end{array}$ & $\begin{array}{l}1220 \text { alunos } \\
\text { com idade } \\
\text { entre } 5 \mathrm{e} \\
18 \text { anos } \\
\text { do ensino } \\
\text { fundamental } \\
\text { e médio } \\
\text { (Elementary, } \\
\text { Middle and } \\
\text { High school). }\end{array}$ & $\begin{array}{l}\text { Analisar a } \\
\text { associação } \\
\text { entre a } \\
\text { percepção } \\
\text { dos pais sobre } \\
\text { a qualidade } \\
\text { nutricional } \\
\text { da AE e o } \\
\text { consumo } \\
\text { desta pelos } \\
\text { alunos. }\end{array}$ & $\begin{array}{l}\text { Entrevista } \\
\text { telefônica com } \\
\text { os pais ou } \\
\text { responsável, com } \\
\text { perguntas sobre } \\
\text { consumo da AE e } \\
\text { sobre a percepção } \\
\text { dos pais quanto } \\
\text { à qualidade } \\
\text { nutricional da } \\
\text { AE, além de } \\
\text { características } \\
\text { sócio } \\
\text { demográficas. } \\
\text { Análises } \\
\text { descritivas, } \\
\text { bivariadas e } \\
\text { regressão logística } \\
\text { multivariada. Valor } \\
\text { de p < } 0,05 \text {. }\end{array}$ & $\begin{array}{l}\text { Entre os alunos } 87,2 \% \text { consomem } \\
\text { a AE. Proporção significativamente } \\
\text { maior de estudantes cujos pais } \\
\text { consideram a AE como pouco saudável } \\
\text { ( } 89 \%) \text { e saudável ( } 92 \%) \text { consumiram } \\
\text { a AE em comparação com os pais } \\
\text { que consideraram a AE pouco ou não } \\
\text { saudável (71,6\%) (p<0,05). } \\
\text { Comparando os alunos cujos pais } \\
\text { perceberam as refeições servidas na } \\
\text { escola como saudável, estudantes } \\
\text { cujos pais perceberam as refeições } \\
\text { como não saudáveis (OR=0,40, } 95 \% \\
\text { CI: } 0,15-1,03) \text { ou pouco não saudável } \\
\text { (OR=0,24, 95\% CI: } 0,11 \text {-0,53) tiveram } \\
\text { menor chance de consumir a AE. A } \\
\text { elegibilidade dos estudantes para as } \\
\text { refeições gratuitas ou a preço reduzido } \\
\text { foi significativamente associada } \\
\text { com maiores chances de estudantes } \\
\text { consumirem a AE (OR=5,59, IC } 95 \% \\
3,03-10,30) \text {. Os estudantes negros } \\
\text { (OR=3,50, CI } 95 \% 1,75-6,99) \text { e } \\
\text { estudantes hispânicos (OR=2,43, IC } \\
\text { 95\% 1,32-4,49) apresentaram chances } \\
\text { significativamente maiores para } \\
\text { consumir a AE em comparação com os } \\
\text { alunos brancos não-hispânicos. }\end{array}$ & $\begin{array}{l}\text { A participação } \\
\text { dos alunos no } \\
\text { programa de } \\
\text { AE foi associada } \\
\text { ao fato dos pais } \\
\text { considerarem a } \\
\text { AE saudável. } \\
\text { Raça e } \\
\text { elegibilidade } \\
\text { à refeições } \\
\text { gratuitas ou a } \\
\text { preço reduzido } \\
\text { também foram } \\
\text { associadas ao } \\
\text { maior consumo } \\
\text { da AE. }\end{array}$ \\
\hline
\end{tabular}


Quadro 2. continuação

\begin{tabular}{|c|c|c|c|c|c|}
\hline $\begin{array}{c}\text { Autor, ano de } \\
\text { publicação } \\
\text { e local do } \\
\text { estudo }\end{array}$ & $\begin{array}{l}\text { Amostra e } \\
\text { abrangência } \\
\text { do estudo }\end{array}$ & Objetivos & $\begin{array}{l}\text { Metodologia/ } \\
\text { Análises } \\
\text { Estatísticas }\end{array}$ & Principais resultados & Conclusões \\
\hline $\begin{array}{l}\text { Smith and } \\
\text { Cunningham- } \\
\text { Sabo (2014), } \\
\text { Colorado } \\
\text { do Norte } \\
(\text { Colorado })^{27}\end{array}$ & $\begin{array}{l}899 \text { alunos } \\
\text { de } 5 \text { escolas } \\
\text { do ensino } \\
\text { fundamental } \\
\text { (Elementary, } \\
\text { Middle } \\
\text { school). }\end{array}$ & $\begin{array}{l}\text { Avaliar as } \\
\text { escolhas } \\
\text { alimentares } \\
\text { e padrões } \\
\text { de consumo } \\
\text { dos alunos } \\
\text { participantes } \\
\text { do NSLP e } \\
\text { comparar } \\
\text { a ingestão } \\
\text { dietética com } \\
\text { as normas do } \\
\text { programa. }\end{array}$ & $\begin{array}{l}\text { Pesagem das sobras } \\
\text { das refeições } \\
\text { (plate waste) } \\
\text { para verificar } \\
\text { desperdício. } \\
\text { Estatística } \\
\text { descritiva e análise } \\
\text { de variância } \\
\text { (ANOVA), }<<0,05 \text {. }\end{array}$ & $\begin{array}{l}\text { Média diária de participação do } \\
\text { NSLP foi de } 70 \% \text { para elementary } \\
\text { school (primeiros anos do ensino } \\
\text { fundamental) e } 57 \% \text { para middle } \\
\text { school (anos finais do ensino } \\
\text { fundamental). Apenas } 45 \% \text { dos } \\
\text { estudantes do elementary school e } \\
34 \% \text { do middle school selecionaram } \\
\text { algum vegetal. Alunos do elementary } \\
\text { school desperdiçaram mais de um } \\
\text { terço dos itens dos grupos dos grãos, } \\
\text { frutas e vegetais. Para alunos do middle } \\
\text { school a taxa foi de quase } 50 \% \text { para } \\
\text { frutas frescas, } 37 \% \text { das conservas de } \\
\text { frutas e quase um terço para vegetais. } \\
\text { Os meninos apresentaram menos } \\
\text { desperdícios para o prato principal e } \\
\text { leite em comparação com as meninas } \\
\text { (p<0,001) }\end{array}$ & $\begin{array}{l}\text { Baixa seleção } \\
\text { e aceitação de } \\
\text { frutas e vegetais. }\end{array}$ \\
\hline
\end{tabular}

tar daquela população, embora haja preferências alimentares por alimentos de baixo valor nutricional, principalmente entre os adolescentes ${ }^{17,34}$.

Essas preferências alimentares se traduzem em outro importante fator associado à adesão à alimentação escolar: presença de cantinas comerciais nas escolas que oferecem opções mais "atraentes" aos estudantes ${ }^{14-16}$.

As cantinas escolares podem comercializar alimentos, que em sua maioria são ricos em gorduras, açúcares e sódio, e contrariam a proposta do PNAE como estratégia de educação nutricional para formação de hábitos alimentares saudáveis. A facilidade de acesso a esses alimentos aliada às preferências dos estudantes, contribuem para menor adesão a AE.

Diante do debate do ambiente escolar como promotor de hábitos alimentares saudáveis, várias cidades e estados adotaram regulamentações que restringem tal comercialização, sendo pioneiro o estado de Santa Catarina, com a publicação, no ano de 2011, da Lei Estadual no $12.061^{35}$. A lei determina a proibição do comércio de bebidas alcoólicas; balas, pirulitos e gomas de mascar; refrigerantes e sucos industrializados; salgados fritos e pipocas industrializadas. Ainda estabelece a obrigatoriedade da oferta de dois tipos de frutas sazonais diariamente. Contudo, Gabriel et al. ${ }^{36}$ apontam que ainda existem escolas que não cumprem as normas de comercialização.

Portanto, cabe ressaltar a importância da realização de ações no contexto da educação alimentar e nutricional. Ações que sejam destinadas não somente aos alunos, mas com o envolvimento de toda a comunidade escolar em projetos que promovam as práticas alimentares saudáveis, e que reconheçam que hábitos alimentares inadequados são reforçados quando há cantinas comerciais com vendas de alimentos contrários aos preconizados pelo PNAE.

O termo "aceitação" da alimentação escolar refere-se à preferência média dos alimentos ofertados pelas escolas. A aceitação constitui um fator importante por refletir a qualidade dos serviços prestados pelas escolas, e pode ser verificada por meio de um teste de aceitabilidade ${ }^{30}$. De acordo com o FNDE, os cardápios deverão ser elaborados tendo por base os hábitos alimentares dos estudantes e apresentar $85 \%$ a $90 \%$ de aceitação ${ }^{7,30}$. Sendo assim, para qualquer alimento inserido no cardápio deve ser realizado teste de aceitabilidade.

Em 2010, o FNDE e o Centro Colaborador de Alimentação Escolar de São Paulo (CECANE/ Unifesp) publicaram o manual de aplicação de testes de aceitabilidade, com objetivo de facilitar 
a sua prática. Esse manual descreve os procedimentos da aplicação do índice de aceitabilidade - método que consiste na pesagem dos alimentos rejeitados - e a escala hedônica, no qual o aluno indica se gosta ou desgosta de um alimento ${ }^{30}$.

Nessa revisão, os estudos brasileiros que avaliaram a aceitabilidade utilizaram questionário com perguntas sobre preferências alimentares como metodologia, e o índice variou entre $70,8 \%{ }^{20}$ e $85,5 \%{ }^{19}$. Contudo, a aceitação efetiva, considerada como "ótima" e "muito boa" por Silva et al. ${ }^{16}$, alcançou apenas $28,8 \%$. Os mesmos autores evidenciaram que idade, gênero, presença de cantinas comerciais e participação em atividades de educação nutricional influenciam na aceitação da $\mathrm{AE}$, assim como encontrado para adesão.

Visto que as preferências alimentares, objeto desses estudos para avaliar a aceitação, deveriam ser consideradas na elaboração dos cardápios da AE, Freitas et al. ${ }^{37}$, em um estudo qualitativo desenvolvido no munícipio da Bahia, com 160 alunos do ensino fundamental e médio, identificaram que, embora os alimentos ofertados na escola sejam de consumo familiar, estes se tornam "estranhos" quando ofertados no horário do intervalo, principalmente em relação à sopa, preparação comum dos cardápios escolares. Para estes estudantes, a sopa deveria ser servida no jantar ou para pessoas enfermas, ou seja, a representação do alimento oferecido no intervalo das aulas também determina o seu consumo.

Segundo esse mesmo estudo, para os adolescentes a hora do recreio/intervalo é vista como um momento de recreação, utilizado para conversar e brincar, combinando com a oferta de lanches e não de refeições com características de almoço ou jantar ${ }^{37}$. Teo et al..$^{20}$ também mencionaram em seu estudo sobre o horário que a alimentação escolar é servida e o tipo de preparação, assim como Muniz e Carvalho ${ }^{17}$, que evidenciaram essa percepção dos alunos em alguns discursos: "só não como a merenda quando é comida de panela, porque eu acho que essas comidas não devem ser oferecidas em um lanche".

É tradição das escolas públicas brasileiras servir a $\mathrm{AE}$ nos intervalos, ou seja, no meio da manhã ou no meio da tarde, entretanto, segundo a resolução vigente do programa, "cabe ao nutricionista responsável técnico a definição do horário e do alimento adequado a cada tipo de refeição, respeitada a cultura alimentar"”.

O horário das refeições na escola deve ser visto como parte do processo pedagógico e de formação de hábitos alimentares, sobretudo, de socialização e interação dos estudantes com os demais membros da comunidade escolar. Sabe-se da dificuldade em se regulamentar os horários na escola, entretanto, adequar os horários e promover um ambiente agradável para o consumo das refeições poderia motivá-los a consumir a AE.

Apesar da qualidade da AE ter melhorado nos últimos anos ${ }^{38}$, principalmente na concepção de que o PNAE atua não somente no controle de riscos nutricionais, mas também como uma política educacional, algumas dificuldades ainda são encontradas nesse processo e também perpassam por questões estruturais das escolas e de gerenciamento (planejamento, cardápios, horários, presença de nutricionista, refeitórios, entre outros), podendo interferir negativamente no consumo da $\mathrm{AE}^{20}$.

\section{Adesão e aceitação à alimentação escolar entre os estudantes nos EUA: NSLP}

Foram encontrados poucos estudos sobre a adesão e aceitabilidade das refeições servidas pelo NSLP, assim como já evidenciado para o PNAE. Entretanto, deve-se ressaltar que o Serviço de Alimentação e Nutrição da USDA administra vários programas que fornecem alimentos ou refeições para crianças e adolescentes americanos, incluindo o School Breakfast Program, o Child and Adult Care Food Program, o Summer Food Service Program, o Fresh Fruit and Vegetable Program e o Special Milk Program, todos com o objetivo de combater as deficiências nutricionais (desnutrição e obesidade) por meio do reembolso às creches, escolas e instituições que fornecem refeições saudáveis aos estudantes ${ }^{39}$.

Nota-se também que a abordagem metodológica diferencia-se entre os estudos. Alguns utilizam como metodologia inquéritos dietéticos, outros analisam dados de registros de distribuição das refeições, o que dificulta comparações assim como para os estudos brasileiros. A adesão encontrada variou entre $56,5 \%{ }^{22}$ e $87,2 \%{ }^{25}$, e os estudos selecionados estão apresentados no Quadro 2.

Observa-se que um dos principais determinantes da adesão ao NSLP, assim como para o PNAE, é a condição socioeconômica do estudante, abordada nos estudos como a elegibilidade à participação gratuita ou a preço reduzido no programa $^{22,24-26}$. Como já citado, o programa americano não tem atendimento universal gratuito, $\mathrm{e}$ os alunos elegíveis às refeições subsidiadas estão suscetíveis ao estigma de que o programa é destinado a alunos de baixa renda e de serem identificados como tal ${ }^{23}$. 
Segundo a lei americana que regulamenta o programa - National School Lunch Act - é proibida a identificação ostensiva de alunos elegíveis para refeições subsidiadas ${ }^{9}$, porém muitas escolas apresentam buffets separados para servir refeições gratuitas e pagas, como também diferentes meios de pagamento que acabam identificando as condições de renda do aluno ${ }^{40}$. A estigmatização é considerada um problema para adesão ao programa por vários autores ${ }^{23,26,40} \mathrm{e}$, mais recentemente, a publicação da regulamentação que apontou novas diretrizes para o NSLP - Healthy Hunger - Free Kids Act of 2010 -, também evidenciou a necessidade de rever mecanismos do programa que levam ao estigma e a expansão da elegibilidade do programa para todos os alunos em áreas americanas mais pobres ${ }^{29}$.

Ainda relacionado a esse aspecto, Bathia et al. ${ }^{23}$ apontam que, em escolas que poucos alunos são beneficiados, a participação no NSLP pode ser facilmente identificada inibindo a adesão ao programa. Já nas escolas em que o maior o número de alunos elege a gratuidade/preço reduzido, maior é a adesão ao programa ${ }^{22}$. Mirtcheva e Powell ${ }^{26}$ evidenciaram que o aumento de $10 \%$ na proporção de alunos elegíveis para a refeição gratuita foi associado ao aumento de 1,8 vezes na probabilidade de participação geral no programa e o aumento de 2,6 vezes para todos os alunos elegíveis à refeição gratuita/preço reduzido.

No período de $2009 / 2010,63 \%$ de todos os alunos matriculados em escolas públicas americanas participaram do NSLP, porém os alunos que eram elegíveis à participação gratuita ou com preço reduzido apresentaram taxas mais elevadas de adesão, $79 \%$ e $73 \%$, respectivamente, do que os alunos não beneficiados $(48 \%)^{11}$.

Aliado a esses resultados, outro fator que interfere na adesão é a presença de alimentos competitivos nas escolas ${ }^{22,23,26}$. Muitos estudantes, principalmente aqueles que apresentam renda mais elevada, preferem comprar alimentos de outros locais para consumirem na escola, afetando negativamente a participação no NSLP26.

Além da oferta da alimentação proveniente do NSLP, lanchonetes, serviços de refeições $a$ la carte, máquinas automáticas com vendas de alimentos e bebidas estão presentes nas escolas americanas $^{10}$. Um estudo desenvolvido nos EUA investigou a associação da venda de alimentos nas máquinas automáticas e o consumo alimentar de 5.930 estudantes durante os anos de 2005 a 2006 e identificou que, das 183 escolas analisadas, $83,1 \%(\mathrm{n}=152)$ tinham máquinas de vendas de alimentos. Entre os resultados encontrados, os autores evidenciaram que os alimentos disponíveis nas máquinas influenciavam o consumo alimentar total do aluno. Por exemplo, os estudantes de escolas que ofertavam doces nas máquinas de venda automática consumiam mais alimentos deste grupo alimentar, quando comparados com os de escolas em que não havia essa oferta ${ }^{41}$.

Contudo, diante da preocupação do governo americano com alta prevalência de obesidade infantil, por meio da publicação da - Healthy Hunger - Free Kids Act of $2010^{29}$ - várias normas foram estabelecidas para melhorar a qualidade dos alimentos ofertados nas escolas. Em relação aos alimentos competitivos, apenas no ano de 2013, o Registro Federal americano normatizou a oferta desses alimentos, estabelecendo que devam ser produtos com mais de 50\% de grãos integrais ou que apresentem como principal ingrediente frutas, vegetais, produtos lácteos ou fontes de proteínas, além de apresentar limites para gorduras, açúcar e sódio, entre outras especificações ${ }^{42}$.

Para Bathia et al. ${ }^{23}$, os alimentos competitivos também são vistos como práticas discriminatórias nas escolas e barreira para participação no NLSP. Seu estudo de intervenção demonstrou que a retirada da oferta de alimentos competitivos das escolas aumentou a participação no NSLP entre alunos elegíveis para a gratuidade ou preço reduzido.

Alimentos competitivos também influenciam a aceitação ao NSLP. Marlette et $\mathrm{al}^{2}{ }^{21}$, evidenciaram que os alunos que compram alimentos competitivos juntamente com a $\mathrm{AE}$, desperdiçam mais frutas, grãos, carnes e pratos mistos. A aceitação e o desperdício de alimentos também são influenciados pelo tipo e método de preparação do alimento ${ }^{21,27}$, demonstrando a questão das preferências alimentares na participação do programa.

A partir do ano de 2012, nova regulamentação para o NSLP foi publicada - Nutrition Standards in the National School Lunch and School Breakfast Programs ${ }^{28}$ - seguindo as diretrizes da Healthy Hunger - Free Kids Act of 2010, e entre as mudanças estão o estabelecimento de limites para o total de calorias e sódio das refeições, a oferta de alimentos mais saudáveis (grãos integrais, frutas e vegetais), a obrigatoriedade de que $\mathrm{o}$ aluno selecione pelo menos três itens alimentares das cinco categorias disponíveis (cereais, carnes, frutas, vegetais e leite), e que uma das opções escolhidas seja do grupo das frutas ou vegetais, além do aumento da porção desses grupos.

Muitos pesquisadores ${ }^{43,44}$ levantaram hipóteses de que essas exigências aumentariam o des- 
perdício dos alimentos pelos alunos. As mudanças impostas são importantes para melhorar a qualidade nutricional do programa, porém ainda é desafiador aumentar a aceitação e o consumo das opções saudáveis, sendo necessário um trabalho de mudanças educacionais e comportamentais no ambiente escolar, dentro do contexto da educação alimentar e nutricional ${ }^{43}$. Aliado a isso, Ohri-Vachaspati ${ }^{25}$ demonstrou também a importância da família nesse processo, visto que a percepção dos pais frente a essas mudanças e a qualidade nutricional da $\mathrm{AE}$ favoreceu a participação dos filhos no NSLP.

\section{Uma comparação dos principais fatores relativos à adesão e aceitação entre os estudantes: PNAE e NSLP}

O PNAE e o NSLP apresentam diferenças importantes quanto ao seu gerenciamento e suas diretrizes, porém conseguiu-se aqui elencar os principais motivos que influenciam na adesão e na aceitação a $\mathrm{AE}$, destacando-se, em ambos os programas, as condições socioeconômicas dos estudantes, a presença de alimentos competitivos no ambiente escolar e as preferências alimentares. O Quadro 3 mostra a comparação estrutural de ambas as políticas em relação a esses fatores.

$\mathrm{O}$ acesso a diferentes alimentos no ambiente escolar americano e brasileiro dá aos estudantes a oportunidade de fazer suas próprias escolhas alimentares. No entanto, sabe-se que a maioria dos alimentos comercializados é rica em gorduras, açúcares e sódio, contribuindo para a formação de hábitos alimentares não saudáveis ${ }^{45}$. Nesse contexto, as regulamentações são importantes para restringir a exposição das crianças e adolescentes a situações de práticas não saudáveis, e os EUA se sobressaem com a publicação de uma regulamentação nacional, diferentemente do caso brasileiro onde ainda tramitam discussões para ampliação nacional.

Contudo, o PNAE diferencia-se pela sua forte abordagem na questão da educação alimentar e nutricional (EAN), sendo um dos seus eixos prioritários juntamente com a oferta de alimentação

Quadro 3. Comparação estrutural do PNAE e do NSLP em relação a fatores de adesão e aceitação a alimentação escolar (AE).

\begin{tabular}{|c|c|c|}
\hline & PNAE - Brasil & NSLP - EUA \\
\hline Acesso à AE & $\begin{array}{l}\text { Atendimento universal a todos os escolares da } \\
\text { rede pública de ensino. }\end{array}$ & $\begin{array}{l}\text { Escolas públicas e privadas podem optar por } \\
\text { participar do programa. }\end{array}$ \\
\hline $\begin{array}{l}\text { Condições } \\
\text { socioeconômicas } \\
\text { dos alunos }\end{array}$ & Todos os alunos recebem refeições gratuitamente. & $\begin{array}{l}\text { Alunos de famílias com renda igual ou inferior } \\
\text { a } 130 \% \text { da linha de pobreza federal recebem as } \\
\text { refeições gratuitamente. Os alunos de famílias } \\
\text { com renda familiar entre } 130 \% \text { e } 185 \% \text { da linha } \\
\text { de pobreza federal podem receber as refeições a } \\
\text { preço reduzido. Os demais, com renda familiar } \\
\text { acima de } 185 \% \text { da linha de pobreza federal, } \\
\text { pagam o preço inteiro pelas refeições }{ }^{10} \text {. }\end{array}$ \\
\hline $\begin{array}{l}\text { Comercialização } \\
\text { de outros } \\
\text { alimentos nas } \\
\text { escolas }\end{array}$ & $\begin{array}{l}\text { Nas escolas brasileiras é permitida a existência } \\
\text { de cantinas comerciais, contudo alguns estados e } \\
\text { municípios desde o ano de } 2011 \text { vêm adotando } \\
\text { regulamentações para proibir a oferta de } \\
\text { alimentos não saudáveis }{ }^{45} \text {. }\end{array}$ & $\begin{array}{l}\text { É permitida a presença de máquinas } \\
\text { automáticas, lanchonetes e serviços a la carte. } \\
\text { Em } 2013 \text { foi publicada a regulamentação da } \\
\text { comercialização desses alimentos competitivos } \\
\text { em todas as escolas americanas, para que sejam } \\
\text { de acordo com as normativas dietéticas daquele } \\
\text { país }{ }^{42} \text {. }\end{array}$ \\
\hline $\begin{array}{l}\text { Cardápios e } \\
\text { preferências } \\
\text { alimentares }\end{array}$ & $\begin{array}{l}\text { Os cardápios devem suprir } 20 \% \text { a } 30 \% \text { das } \\
\text { necessidades nutricionais dos estudantes que } \\
\text { permanecem em período parcial na escola, } \\
\text { e utilização de gêneros alimentícios básicos, } \\
\text { respeitando-se as referências nutricionais, } \\
\text { os hábitos alimentares, a cultura e a tradição } \\
\text { alimentar da localidade, pautando-se na } \\
\text { sustentabilidade e diversificação agrícola da } \\
\text { região, na alimentação saudável e adequada }\end{array}$ & $\begin{array}{l}\text { Os cardápios devem ser elaborados de } \\
\text { acordo com as normativas dietéticas } \\
\text { americanas, contudo as decisões com } \\
\text { relação a determinados alimentos e tipos de } \\
\text { preparação oferecidos são feitos pelas agências } \\
\text { administradoras locais, o que possibilita que as } \\
\text { escolas respeitem as preferências e os hábitos } \\
\text { regionais dos escolares }{ }^{28} \text {. }\end{array}$ \\
\hline
\end{tabular}


adequada e saudável e o apoio ao desenvolvimento sustentável com incentivos para a aquisição de gêneros alimentícios provenientes da agricultura familiar. Conquistas advindas da publicação da lei no 11.947 , no ano de $2009^{6}$.

Tal regulamentação inclui a EAN no processo de ensino e aprendizagem dentro do currículo escolar, sendo fortalecida com a publicação da resolução do FNDE n²6, de 17 de junho de $2013^{7}$. A resolução traz uma seção dedicada às ações que devem ser realizadas, conceituando EAN como: "conjunto de ações formativas, de prática contínua e permanente, transdisciplinar, intersetorial e multiprofissional, que objetiva estimular a adoção voluntária de práticas e escolhas alimentares saudáveis que colaborem para a aprendizagem, o estado de saúde do escolar e a qualidade de vida do indivíduo"7.

Sabe-se da importância da EAN como estratégia fundamental para a prevenção e controle dos problemas alimentares e nutricionais atuais e de transformar a escola em um local privilegiado de promoção da saúde, promovendo a autonomia de escolhas mais saudáveis. Assim, a EAN atua fortemente em combater alguns dos fatores que influenciam a não adesão à AE, como a escolha dos alimentos competitivos e as preferências alimentares não saudáveis dos estudantes.

No EUA, existem algumas ações dentro do NSLP, como a Local School Wellness Policy ${ }^{46}$ que exigiu que, a partir do ano letivo de 2006/2007, todas as escolas deveriam estabelecer uma política de bem-estar nas instituições que envolvem, entre outros setores, a promoção e a educação nutricional. No entanto, não possui o caráter es- trutural como as ações de EAN propostas pelo PNAE. Outro programa gerenciado pela USDA, o Expaned Food and Nutrition Education Program (EFNEP), tem o objetivo de realizar educação nutricional para as famílias mais carentes, incluindo crianças e adolescentes, com atividades sobre nutrição, preparação de alimentos, segurança alimentar, atividade física e saúde ${ }^{47}$.

\section{Considerações finais}

Os principais fatores que influenciam na adesão e aceitação da alimentação escolar em ambos os programas são semelhantes, ou seja, às condições socioeconômicas dos alunos, presença dos alimentos competitivos no ambiente escolar e as preferências alimentares. Contudo, o gerenciamento dos mesmos diferencia-se principalmente no que diz respeito ao atendimento. No EUA o estigma de programa para crianças carentes é elencado como barreira de adesão ao NSLP, visto que apenas os alunos desfavorecidos economicamente recebem as refeições gratuitas, porém no Brasil mesmo com atendimento universal gratuito, a adesão encontrada também é baixa.

Assim, mesmo com os avanços ao longo da existência desses programas, ainda existem desafios para que o fornecimento de refeições saudáveis atinja seu público alvo. Estudos que investiguem esses desafios contribuem para que os governos e gestores fortaleçam e aprimorem seus programas, além de potencializar a utilização dos recursos financeiros públicos que são investidos.

\section{Colaboradores}

JT Cesar e EA Valentim trabalharam na concepção, delineamento, interpretação dos dados e redação do artigo; CCB Almeida e MEM Schieferdecker na revisão crítica do artigo e ST Schmidt na orientação, revisão crítica e aprovação da versão a ser publicada. 


\section{Referências}

1. World Food Program (WFP). State of School Feeding Worldwide. Canada International Development Agency; 2013.

2. Food and Agriculture Organization of the United State (FAO). Food Security. Policy Brief, June 2006, Issue 2. [acessado 2015 Set 10]. Disponível em: http://www. fao.org/forestry/13128-0e6f36f27e0091055bec28ebe830f46b3.pdf.

3. Food and Agriculture Organization of the United State (FAO). O estado da segurança alimentar e nutricional no Brasil um retrato multidimensional. Relatório 2014. Brasília, Ago de 2014. [acessado 2015 Set 10]. Disponível em: https://www.fao.org.br/download/SOFI_p.pdf

4. Brasil. Lei 11.346, de 15 de setembro de 2006. Cria o Sistema Nacional de Segurança Alimentar e Nutricional - SISAN com vistas em assegurar o direito humano à alimentação adequada e dá outras providências. (Lei Orgânica de Segurança Alimentar e Nutricional). Diário Oficial da União 2006; 15 set.

5. Hoffmann R. Determinantes do consumo da merenda escolar no Brasil: análise dos dados da PNAD de 2004 e 2006. Rev Segurança Alimentar e Nutricional 2012; 19(1):33-45.

6. Brasil. Lei no 11.947, de 16 de junho de 2009. Dispõe sobre o atendimento da alimentação escolar e do Programa Dinheiro Direto na Escola aos alunos da educação básica. Diário Oficial da União 2009; 17 jun.

7. Brasil. Resolução CD/FNDE no 26 , de 17 de junho de 2013. Dispõe sobre o atendimento da alimentação escolar aos alunos da educação básica no âmbito do Programa Nacional de Alimentação Escolar - PNAE. Diário Oficial da União 2013; 18 jun.

8. Fundo Nacional de Desenvolvimento da Educação (FNDE). Dados Estatísticos do PNAE. [acessado 2015 Set 10]. Disponível: http://www.fnde.gov.br/programas/alimentacao-escolar/alimentacao-escolar-consultas/alimentacao-escolar-dados-estatisticos

9. United States. Richard B. Russell National School Lunch Act of 1946, pub.n $.79-396,1946 ; 4$ jun.

10. United State Department of Agriculture (USDA).The National School Lunch Program: Background, Trends, and Issues. Economic Research Service 2008; n61.

11. United State Department of Agriculture (USDA). School Nutrition Dietary Assessment Study-IV, Vol. I: School Food service Operations, School Environments, and Meals Offered and Served. Office of Research and Analysis, nov 2012.

12. United States Department of Agriculture (USDA). National School Lunch Program, 2013 [Internet]. 2014. [acessado 2015 Set 10]. Disponível em: http://www.fns. usda.gov/sites/default/files/NSLPFactSheet.pdf

13. Mendes KDS, Silveira, RCCP, Galvão CM. Revisão integrativa: método de pesquisa para a incorporação de evidências na saúde e na enfermagem. Texto Contexto Enferm 2008; 17(4):758-764.
14. Sturion GL, Silva MV, Ometto AMH, Furtuoso MCO, Pipitone MAP. Fatores condicionantes da adesão dos alunos ao Programa de Alimentação Escolar no Brasil. Rev Nut 2005; 18(2):167-181.

15. Hernandez AB, Slavutzky SMB, Padilha DMP. Avaliação do consumo da merenda escolar em escolas municipais de Porto Alegre. Rev Fac Odonto. Porto Alegre 2008; 49(1):26-30.

16. Silva CAM, Marques LA, Bonomo E, Bezerra OMPA, Corrêa MS, Passos LSF, Souza AA, Barros BF, Souza DMS, Reis JA, Andrade NG. O Programa Nacional de Alimentação Escolar sob a ótica dos alunos da rede estadual de ensino de Minas Gerais, Brasil. Cien Saude Colet 2013; 18(4):963-969.

17. Muniz VM, Carvalho AT. O Programa Nacional de Alimentação Escolar em município do estado da Paraíba: um estudo sob o olhar dos beneficiários do Programa. Rev Nut 2007; 20(3):285-296.

18. Flávio EF, Barcelos MFP, Lima AL. Avaliação química e aceitação da merenda escolar de uma escola estadual de Lavras-MG. Cienc agrotec 2004; 28(4):840-847.

19. Barros MS, Fonseca VM, Meio MDBB, Chaves CR. Excesso de peso entre adolescentes em zona rural e a alimentação escolar oferecida. Cad Saude Colet 2013; 21(2):201-208.

20. Teo CRPA, Corrêa EN, Gallina LS, Fransozi C. Programa nacional de alimentação escolar: adesão, aceitação e condições de distribuição de alimentação na escola. Nutrire: Rev Soc Bras Alim Nutr 2009; 34(3):165-185.

21. Marlette MA, Templeton SB, Panemangalore M. Food Type, Food Preparation, and Competitive Food Purchases Impact School Lunch Plate Waste by SixthGrade Students. J Am Diet Assoc 2005; 105(11):17791782.

22. Probart C, McDonnell E, Hartman T, Weirich JE, Bailey-Davis L. Factors Associated with the Offering and Sale of Competitive Foods and School Lunch Participation. J Am Diet Assoc 2006; 106(2):242-247.

23. Bhatia R, Jones P, Reicker Z. Competitive Foods, Discrimination, and Participation in the National School Lunch Program. Am J Public Health 2011; 101(8):13801386.

24. Hernandez DC, Francis LA, Doyle EA. National School Lunch Program Participation and Sex Differences in Body Mass Index Trajectories of Children From Low-Income Families. Arch Pediatr Adolesc Med 2011; 165(4):346-353

25. Ohri-Vachaspati. Parental perception of the nutritional quality of school meals and its association with students' school lunch participation. Appetite 2014; 74:4447.

26. Mirtcheva DM, Powell LM. Participation in the National School Lunch Program: Importance of School-Level and Neighborhood Contextual Factors. J Sch Health 2009; 79(10):485-494. 
27. Smith SL, Cunningham-Sabo L. Food choice, plate waste and nutrient intake of elementary and middle-school students participating in the US National School Lunch Program. Public Health Nutr 2013; 17(6):1255-1263.

28. United States Department of Agriculture (USDA). Nutrition Standards in the National School Lunch and School Breakfast Programs; Final Rule. Federal Register 2012; 77(17):4088-4167.

29. United States. Public Law 111-296. Healthy, Hunger-Free Kids Act of 2010. 2010, $13 \mathrm{dec}$

30. Centro Colaborador em Alimentação e Nutrição Escolar (CECANE/UNIFESP). Manual para aplicação dos testes de aceitabilidade no Programa Nacional de Alimentação Escolar - PNAE. Brasília: CECANE/UNIFESP; 2010.

31. Kepple AW, Gubert MB, Corrêa MAS. Instrumentos de Avaliação de Segurança Alimentar e Nutricional. In: Taddei JA, Lang RMF, Longo-Silva G, Toloni MHA, organizadores. Nutrição em Saúde Pública. Rio de Janeiro: Editora Rubio; 2011. p. 73-97.

32. Instituto Nacional de Alimentação e Nutrição (INAN). Pesquisa Nacional sobre Saúde e Nutrição: Resultados preliminares. Brasília: INAN; 1990.

33. Bezerra JAB. Alimentação e escola: significados e implicações curriculares da merenda escolar, Rev Bras Educ 2009; 14(40):103-115.

34. Instituto Brasileiro de Geografia e Estatística (IBGE). Pesquisa Nacional de Saúde do Escolar. Rio de Janeiro: IBGE; 2009

35. Santa Catarina. Lei $\mathrm{n}^{\circ} 12.061$, de 18 de dezembro de 2001. Dispõe sobre critérios de concessão de serviços de lanches e bebidas nas unidades educacionais, localizadas no Estado de Santa Catarina. Diário Oficial do Estado 2001; $20 \mathrm{dez}$

36. Gabriel CG, Santos MV, Vasconcelos FAG, Milanez GHG, Hulse SB. Cantinas escolares de Florianópolis: existência e produtos comercializados após a instituição da Lei de Regulamentação. Rev Nutr 2010 23(2):191-199.

37. Freitas MCS, Minayo MCR, Ramos LB, Fontes GV, Santos LA, Souza EC, Santos AC, Mota SE, Paiva JB, Bernardelli T, Demétrio F, Menezes I. Escola: lugar de estudar e de comer. Cien Saude Colet 2013; 18(4):979-985.

38. Peixinho AML. A trajetória do Programa Nacional de Alimentação Escolar no período de 2003-2010: relato do gestor nacional. Cien Saude Colet 2013; 18(4):909916.

39. United States Department of Agriculture (USDA). School Meals. Child Nutrition Programs. [acessado 2015 Set 01]. Disponível em: http://www.fns.usda.gov/school-meals/child-nutrition-programs

40. Segregated lunch lines and payment methods for NSLP reimbursable meals vs. a la carte food: a legal analysis. San Francisco: Public Advocates Inc; 2009.
41. Rovner AJ, Nansel TR, Wang J, Iannotti RJ. Food Sold in School Vending Machines Is Associated With Overall Student Dietary Intake. J Adolesc Health 2011; 48(1):13-19.

42. United States Department of Agriculture (USDA). National School Lunch Program and School Breakfast Program: Nutrition Standards for All Foods Sold in School as Required by the Healthy, Hunger Free Kids Act of 2010. Interim final rule. Federal Register 2013; 78(125):39068-39120.

43. Gase LN, McCarthy WJ, Robles B, Kuo T. Student receptivity to new school meal offerings: Assessing fruit and vegetable waste among middle school students in the Los Angeles Unified School District. Prev Med 2014; 67(1):28-33

44. Cohen JFW, Richardson S, Parker E, Catalano PJ, Rimm EB. Impact of the New U.S. Department of Agriculture School Meal Standards on Food Selection, Consumption, and Waste. Am J Prev Med 2014; 46(4):388-394.

45. Brasil. Ministério da Saúde (MS). Experiências estaduais e municipais de regulamentação da comercialização de alimentos em escolas no Brasil: identificação e sistematização do processo de construção e dispositivos legais adotados. Brasília: MS; 2007.

46. United State Department of Agriculture (USDA). Local School Wellness Policy Implementation Under the Healthy, Hunger-Free Kids Act of 2010. Federal Register 2014; 79(38):10693-10706.

47. United State Department of Agriculture (USDA). Expanded Food and Nutrition Education Program (EFNEP). [acessado 2015 Ago 25]. Disponível em: http:// nifa.usda.gov/program/expanded-food-and-nutrition -education-program-efnep.

Artigo apresentado em 28/10/2015

Aprovado em 23/06/2016

Versão final apresentada em 25/06/2016 
